\title{
Práticas de Glosa e Anamnese
}

\author{
CLAUDIO CHAVES BEATO FILHO *
}

Um dos elementos essenciais à confecção de diagnósticos médicos é a anamnese realizada com os pacientes, mediante a qual se buscam elementos em sua biografia que corroborem alguma hipótese de diagnóstico. Trata-se de uma tarefa essencialmente interpretativa, em que há uma relação reflexiva entre as hipóteses formuladas pelos médicos e os comportamentos e motivações associados ao diagnóstico.

Uma questão crucial, para efeitos práticos da atividade médica, é a de quando deve cessar o processo interpretativo. Em termos fenomenológicos, trata-se de saber como é possível evitar o círculo de "interpretação das interpretações" que conduziria a interação médico/paciente a uma regressão ao infinito, o que terminaria por inviabilizar a própria interação. Minha hipótese é a de que este é um problema que é resolvido em contextos específicos de ação, mediante a adoção de práticas de glosa que estabilizam o sentido da interação para efeitos práticos.

* Doutor em Ciências Humanas pelo IUPERJ e Professor Adjunto do Departamento de Sociologia e Antropologia, e dos programas de Mestrado em Sociologia e Doutorado em Sociologia Política da Universidade Federal de Minas Gerais. Tem atuado nas áreas de Sociologia das Profissōes, Sociologia do Conhecimento Científico, Teoria Social e Metodologia e Criminalidade e Violência. 


\section{O problema da descrição}

Relatos, tais como as anamneses realizadas pelos médicos no atendimento de pacientes categorizados como suicidas, ${ }^{1}$ compartilham dos mesmos problemas de outras formas de descrição. A solução desses problemas é necessária para que o relato emerja como uma peça narrativa factível perante outros membros da comunidade profissional.

Segundo uma estratégia muito comum às vertentes teóricas que compõem as perspectivas absolutistas, ${ }^{2}$ signos têm um significado único e inequívoco, passível de leitura literal e de uma interpretação totalmente desvinculada do contexto social que envolve o sistema simbólico. Trata-se, contudo, de uma crença de senso comum que a realidade social está sujeita a uma leitura dessa natureza. Por outro lado, em algumas versões interpretativas mais radicais são possíveis tantos pontos de vista quanto referentes tomados. Cada comunidade desenvolve as referências interpretativas que balizam as descrições. ${ }^{3} \mathrm{Na}$ vida prática, entretanto, operamos com um estoque limitado de esquemas interpretativos para a interpretação de situações cotidianas, tornando finito o número de possibilidades de descrição. Para que essas possibilidades existam, é necessário, em uma interpretação wittgensteiniana, que elas sejam entendidas pelos outros membros da comunidade em jogos de linguagem cujas regras são do conhecimento comum. Portanto, significados são compreendidos em situações de linguagem, e não em referência a alguma coisa; não são elementos invariantes tais como rótulos a serem utilizados oportunamente, mas definem-se nos contextos específicos de sua utilização. A montagem e a compreensão de uma descrição emergem na forma de um contexto cultural mais amplo, que é o resultado, mas ao mesmo tempo fornece aos falantes e ouvintes os esquemas interpretativos adequados a essa compreensão.

A estratégia epistemológica das teorias da correspondência repousa na crença de que é possível produzir relatos da vida social desindexicalizados, universalmente orientados e independentes do contexto em que foram produzidos, isto é, literais. Assim, as fichas de atendimento estariam reproduzindo, literalmente, as condições físicas e psicológicas dos pacientes, ainda que

1. C. C. Beato Filho, "Médicos, Suicidas e Senso Prático", Revista Brasileira de Ciências Sociais, ano 6, $\mathrm{n}^{0} 15$, fevereiro de 1991, pp. 53-63.

2. B. Barnes e J. Law, "Whatever should Be Done with Indexical Expressions?", Theory and Society, vol. 3, $\mathrm{n}^{2} 2,1976$.

3. S. Fish, Is There a Text in this Class? The Authority of Interpretive Communities, Cambridge, Harvard University Press, 1980. 
somente para efeitos práticos das atividades do Serviço. Entre os plantonistas, não se coloca em questão as informações ali contidas, especialmente as que se supõe de caráter meramente técnico, tais como informações sobre as condições físicas dos pacientes. Dados mensuráveis por meio de instrumentos não necessitam de operações de reparo de elementos indéxicos para serem compreendidos. ${ }^{4} \mathrm{~A}$ temperatura corporal adequada, ou o número de batimentos cardíacos de algum paciente são informações factuais, indicando a possibilidade de leituras literais do texto, ainda que possamos imputar algum grau de indeterminação na anamnese realizada com os pacientes. Contudo, conforme argumentarei, é a utilização de estratégias específicas que permite que esses dados emerjam como dotados de propriedades factuais.

\section{Práticas de glosa e relatos médicos}

Isso é possível somente em virtude de práticas de glosa (glosses practices) utilizadas pelos plantonistas nas descrições de seus pacientes e realizadas por intermédio das fichas médicas. Um plantonista não tem que dar esclarecimentos constantes aos outros membros da comunidade profissional sobre o sentido das afirmações contidas nos relatos. Pelo contrário, os contextos em que as descrições surgem não são informações relevantes a serem levadas em consideração por outros plantonistas. Raramente é necessário explicitar as circunstâncias em que os relatos foram produzidos para que seu sentido seja compreendido por outros membros da comunidade. O suposto é o de que ali está encoberta uma série de práticas que são do domínio comum dos membros do Serviço, de tal forma que detalhes indéxicos são abstraídos. ${ }^{5}$ Podemos dizer que as práticas de glosa se constituem em formas

4. Existem posições tais como a do próprio Garfinkel, e discutidas extensivamente por B. Barnes e J. Law, "Whatever should...”, op. cit., para quem a indexicalidade é universal e os reparos uma atividade interminável. Em um sentido lógico e abstrato isto é verdade. Entretanto, estou tratando da "lógica-em-uso" dos plantonistas no intuito de mostrar como esta lógica utiliza glosas como estratégia para conferir objetividade às suas descriçōes. Esta me parece ser uma discussāo natural derivada de H. Garfinkel e J. Sacks, “On Formal Structures of Practical Actions”, in McKinney e Tyriakian, Theoretical Sociology: Perspectives and Development, Nova Iorque, Appleton-Century Crofts, 1970, pp. 338-66, conforme veremos adiante.

5. A idéia de práticas que sāo dissimuladas surge da própria raiz etimológica do termo glosa, que em grego quer dizer "termo obscuro". O termo refere-se a uma nota explicativa de um texto que necessariamente nāo aparece no corpo do próprio texto. No caso, o que está implícito é uma série de procedimentos apreendidos mediante a socializaçāo profissional. 
abreviadas para o reconhecimento e compreensão do que, como, por quem e para quem é dito. São, portanto, métodos para compreendermos eventos como observáveis e reportáveis, isto é, como relatos.

As fichas médicas representam uma interessante ilustração da utilização de glosas no sentido de o texto ser apreciado independentemente do contexto específico em que foi gerado. Embora tais contextos sejam decisivos na elaboração dos relatos, não necessitam ser explicitados para que outros membros da comunidade os compreendam. Os relatos surgem da interação de duas formas cognitivas: o conhecimento "declarativo" e o conhecimento "processual”. O primeiro diz respeito às orientaçōes mais gerais da disciplina médica e constitui a essência da formação educacional da profissão. $O$ segundo, embora seja um componente ativo na socialização profissional, é um conhecimento gerado a partir de situações e contextos específicos. Os elementos indéxicos constitutivos desses contextos e situações são abstraídos pelos outros membros do plantão, em uma estratégia denominada como uma prática de glosa. Esta possibilidade de abstração dos elementos indéxicos é um aspecto fundamental que faz com que a atividade dos médicos plantonistas seja distinta da de outros profissionais. Aliás, o plantão em hospitais constitui-se em uma instância decisiva na socialização profissional dos médicos, cujo objetivo é a vivência prática. Esta é que possibilita a operação das práticas de glosa, permitindo que os relatos sejam concebidos como descriçōes "objetivas" a respeito das condições dos pacientes:

\footnotetext{
"A associação profissional consiste na disponibilidade de leitores competentes e circunstâncias não explicadas sobre as quais aquele tipo de escrito torna-se glosado. Via associaçăo, definiçōes de sentido e facticidade do relato sāo intimamente vinculadas aos ambientes do diálogo, dispositivos de conversaçāo, 'maquinaria' dialógica na qual e por meio da qual o que realmente e não supostamente reportado terá sido 'visto pelo dizer' ter sido escrito em tantas palavras". ${ }^{6}$
}

Os relatos contidos nas fichas de atendimento consistem em formulações que procuram "dizer-numas-tantas-palavras-o-que-estamos fazendo" (saying-inso-many-words-what-we-are-doing), para que os outros plantonistas possam prosseguir rotineiramente suas atividades. O que está sendo formulado nos relatos enfatiza algumas características constitutivas do diálogo travado entre médicos, pacientes, parentes e/ou relativos que não estão visíveis imediatamente nas fichas. Não sabemos qual o sentido exato das motivaçōes ali contidas, nem qual a conexão entre elas e a confecção de um diagnóstico, pelo

6. H. Garfinkel e J. Sacks, “On Formal Structures..., op. cit. 
simples fato de não sermos membros da comunidade profissional. Para os plantonistas, entretanto, eles constituem declarações transparentes, precisas e universais sobre as condições dos pacientes. Sua objetividade, além disso, destaca o caráter "ocasionado" das formulações contidas nas descrições.?

A relação entre a descrição, os eventos e os objetos particulares descritos explicita-se no relato a partir das atividades de glosa, que tornam possível que os elementos indéxicos da descrição sejam abstraídos. É a esta intensa e contínua atividade interpretativa que Garfinkel denomina como o "trabalho" realizado pela descrição, querendo com isso ressaltar o caráter dinâmico e ativo do empreendimento de transformar fenômenos sociais em relatos. Neste sentido, este artigo pretende ser justamente uma discussão a respeito do "trabalho" dos médicos.

Elaborar formulações, portanto, é uma forma de se restabelecer as propriedades indéxicas das descrições. É nesse momento que as práticas de glosa se constituem em uma estratégia crucial para a confecção de relatos. Como relatos são "fenômenos essencialmente contextualizados", que exigem o reconhecimento de quem, para que, quando e para quem são feitos, a tarefa de resgate de indexicalidades virtualmente paralisaria as atividades dos plantonistas, em favor de uma pesquisa incessante do sentido exato dos elementos descritivos contidos na ficha de atendimento. Assim, o exame dos elementos indéxicos transformar-se-ia em uma regressão infinita, posto que a cada conjunto de expressões indéxícas examinadas surgiria um novo contexto, o que levaria a um novo conjunto de redefinições, e assim por diante. Garfinkel e Sacks observam que os elementos indéxicos do relato "são sem remédio no sentido de que toda medida tomada na direção de um remédio preserva e especifica as características pelas quais o remédio foi utilizado. ${ }^{8}$

\section{A estrutura gestáltica das fichas de atendimento}

Algumas versões importantes a respeito da indexicalidade postulam justamente a sua universalidade. Segundo essas interpretações, seria impossível

7. Idem.

8. Idem, p. 356. A esse comentário podemos ainda aduzir o argumento de Peyrot (1982, p. 271), apud Freitas, 1990: “Assim, se o item original não é intrinsecamente significativo, sua revisāo também nāo pode ser. Se, por outro lado, o item original (ou qualquer outro) é intrinsecamente significativo, pode ser possível remediar uma leitura particular dele, como a 'ambígua'. Entender mal um item ou lê-lo como ambíguo é sempre possível, mas isso não significa que esse item (ou qualquer outro) é essencialmente ambíguo ou além do entendimento". 
concebermos a existência de uma ordem de descrições desindexicalizadas, mesmo aquelas que julgamos como dados puramente factuais, como a medida de um termômetro por exemplo, ou o resultado de proposiçóes exclusivamente lógicas, como a demonstração de um teorema. Quaisquer ordens de proposiçōes resultam de uma série de operações visando justamente a "reparação" da indexicalidade inerente às descrições, indicando assim uma contextualidade histórica e localmente conformada. Assim, podemos argumentar que a discussão a respeito do sentido exato dos elementos contidos na anamnese se estende integralmente a todos os aspectos do exame físico, de tal maneira que estes passam a ser interpretados como documentos em ação, e não como "retratos" de uma situação. Por outro lado, os aspectos arrolados durante o exame físico atuam no sentido de "reparar" os elementos indéxicos contidos na descrição fornecida pelos pacientes durante a anamnese. Esta atividade só é possível mediante a crença de que os dados resultantes do exame físico constituem-se em uma descrição literal das condiçôes físicas dos pacientes.

Uma outra maneira de abordarmos a indexicalidade presente nas descrições seria postularmos o caráter único e ocasionado dos relatos sociais para, então, verificarmos as condiçōes e métodos que operam na demonstração dos mesmos. Um dos equívocos na consideração das descrições consiste na idéia de que, dado seu caráter negociado com "base no que todo mundo sabe", relatos são essencialmente imprecisos e ambíguos. Mas são, justamente, os esquemas e procedimentos interpretativos à disposição dos atores sociais que entram em ação a cada cenário social que possibilitam uma leitura objetiva de eventos e ações como se fossem dotados de propriedades factuais.

Gostaria de ressaltar algumas implicações equivocadas que, porventura, possam surgir em relação ao caráter ocasionado dos relatos, sugerindo que o que está em questão é a idéia de que fenômenos sociais são sempre particulares, nunca generalizáveis, e cuja estrutura somente pode ser apreciada a partir de uma lógica indutiva. Não se está afirmando que situaçōes tais como as descritas nos pronto-socorros nos são vedadas em função do caráter único e irredutível das experiências humanas. Levado a extremos, isso corresponderia à idéia presente em algumas versões fenomenológicas de que é impossível reelaborarmos e reinterpretarmos um sistema de signos em sua totalidade, visto que seu sentido é único e intraduzível em outros jogos de linguagem. Nenhum código simbólico poderia ser "traduzido" ou "compreendido" em outras formas cognitivas. Entretanto, a posiçāo da etnometodologia, bem como da filosofia da linguagem, é a de opor-se 
frontalmente a quaisquer formas de reificaçāo de jogos de linguagem. Da mesma maneira que as práticas de glosa possibilitam aos ouvintes a abstração do contexto utilizado pelos descritores, estratégias cognitivas similares atuam no sentido de traduzir sistemas simbólicos para outros sistemas.

Quando lidam com relatos deixados por colegas de outros turnos, os plantonistas não se preocupam com detalhes contextuais tais como o fato de a família estar ou não presente no momento da internação do paciente, expressões faciais ou desempenhos cênicos. Essa liberdade de leitura do texto é que torna possível que as informaçōes emerjam como dotadas de propriedades factuais. A prática da glosa constitui-se em uma estratégia interpretativa que possibilita uma leitura sem obstáculos dos relatos.

Sem esse procedimento, as informações contidas nos relatos requereriam uma sucessão interminável de "explicações" e "clarificaçōes" de informaçōes contextuais, o que virtualmente paralisaria a descrição. Imaginem, por exemplo, um médico que no afã da objetividade, terminasse às voltas com questões como "o que os familiares queriam me dizer quando falaram que o paciente nāo estava bem nos últimos dias?" ou, "quantos comprimidos exatamente foram ingeridos por aquele paciente em coma?", e assim por diante. Certamente, o atendimento seria interrompido em função de respostas impossíveis de serem obtidas. Para efeitos práticos, os médicos julgam seus casos de acordo com critérios imediatamente visíveis, o que torna possível um diagnóstico adequado. Qual é o peso de tais critérios é uma questāo que será discutida um pouco mais adiante.

Por ora, gostaria de acentuar a determinação reflexiva do significado das situaçōes vividas pelos plantonistas, a partir das quais os relatos podem ser considerados como documentos adequados aos propósitos dos mesmos. $\mathrm{O}$ próprio fato de tomarem as fichas de atendimentos realizados por outros colegas como uma indicação inicial do estado dos pacientes significa que estas são apreciadas em sua função documental, exercendo o papel de um padrão inicial a partir do qual se examinam os pacientes.

O centro composto pelos elementos indéxicos e reflexivos da descrição constitui-se na "estrutura gestáltica" do significado, ${ }^{9}$ que Garfin kel concebe como o centro do método documentário interpretativo. É em virtude da articulação entre elementos indéxicos e das determinações de natureza reflexiva que o relato se torna reconhecível para o ouvinte e para o descritor. Esse processo envolve pelo menos duas grandes questões a serem respondi-

9. J. Heritage, "Aspects of the Flexibilities of Language Use: A Reply to Phillips", Sociology, vol. 12, 1978, pp. 79-103. 
das: (1) o problema da indeterminação dos critérios a partir dos quais se julga fenômenos como semelhantes; e (2) o problema da multiplicidade de interpretações. Estas são basicamente as grandes questões enfrentadas pelos plantonistas na confecção dos relatos. Para resolvê-las adequadamente, algumas regras atuam no sentido de normatizar comportamentos e atitudes em torno de um conjunto de traços básicos que podem ser reconhecidos como "semelhanças de família". ${ }^{10} \mathrm{O}$ elenco de características rotineiramente utilizadas na qualificação de suicidas abrange, sucintamente, os seguintes elementos:

1. Cenário de atendimento.

2. Sexo, idade e estado civil.

3. Problemas familiares.

4. Pacientes psiquiátricos.

5. Comportamentos desviantes.

Cada um desses critérios envolve uma série de decisões a serem tomadas com base em informações a respeito das características dos pacientes. Assim, em (1) são levados em conta aspectos cênicos do atendimento, tais como o horário, a presença ou não de familiares, "teatralidade" dos pacientes, quem são os acompanhantes, grau de consciência dos pacientes ou reações aos testes de reflexos. Em (2) as evidências adscritas sobre os pacientes não são tomadas isoladamente, mas em conjunto. Assim, esperase que mulheres mais novas e solteiras sejam mais propensas a "problemas de relacionamento", por exemplo, ou que senhỏres ou senhoras já de meiaidade, separados por algum motivo de seus companheiros, sejam candidatos ao auto-extermínio e assim por diante. (3) Brigas com familiares próximos são consideradas como detonadores de comportamentos suicidas. (4) Pacientes que porventura se encontrem em algum processo terapêutico psiquiátrico são mais sujeitos a serem considerados como candidatos ao autoextermínio, em virtude de: (a) terem um meio à disposição, que são os remédios tomados, e (b) serem pessoas psicologicamente mais frágeis. Qualquer dos dois elementos é decisivo, pois há casos em que (b) não está presente, mas (a) é causa suficiente, como no caso dos pacientes epiléticos. De qualquer maneira, (b) é uma informação crucial para a definição da conduta terapêutica a ser adotada. E, finalmente, em (5) pacientes com conduta desviante, tais como drogados, homossexuais ou prostitutas, cujos

10. Idem. 
comportamentos freqüentemente são considerados como moralmente problemáticos, tornam-se candidatos ao auto-extermínio.

Esse elenco de características acarreta alguns problemas em relação à decisão de qual delas deve ser decisiva na categorização de uma tentativa de auto-extermínio. Em última análise, isso corresponde à questão de qual a base cognitiva que permite que fenômenos tais como suicídios e tentativas de suicídio sejam considerados como eventos similares, o que é imediatamente relacionado à questão de qual é a causa desses eventos. Trata-se de categorias descritivas cuja utilização depende de uma série de critérios que estão à disposição do descritor para a caracterização da situação. A escolha desses critérios não envolve uma decisão em abstrato, ou seja, um deles deve "pesar mais" que os outros. É da interpretação dos elementos contidos nos relatos dos pacientes e/ou de seus relativos que emergirão os critérios relevantes a cada contexto.

Assim, (1) e (2) são decisivos para a categorização do caso relatado no texto 1-b em Apêndice; (3) constitui-se na dimensão mais relevante nos textos 1-a e 1-c; e (5) será fundamental no texto 1-d. É a partir desses critérios que serão articuladas as descrições daqueles fenômenos específicos. Não se trata, portanto, da utilização de uma regra específica para a aplicação das categorias, mas de "práticas" que são "vistas mas não noticiadas" (seen but unnoticed), que visam "reparar" a indefinição potencial presente nos relatos transmitidos aos outros plantonistas. As decisões a que os plantonistas chegam na caracterização dos casos envolvem a comparação de critérios incomensuráveis entre si, não existindo uma regra que os oriente em sua decisão, mas uma prática:

\footnotetext{
"Regras semânticas ou descritivas não existem em um gabinete de arquivamento mental esperando aplicações não problemáticas. Pelo contrário, para membros e analistas, a seleçāo dos descritores para caracterizar cenários (que poderiam ser caracterizados indefinidamente de muitas maneiras) é entendida como sensitiva para o que poderia ser alcançado em e por meio da provisāo de tais descriçōes. De fato, a seleçāo de descritores deveria examinar o que o descritor está compreensivelmente tentando fazer com sua descriçāo e, inversamente, o que um descritor é entendido como tentando fazer (inferido nos limites seqüenciais e/ou contextuais) possa ser utilizável para localizar e entender o descritor". ${ }^{11}$
}

É nessa relação reflexiva entre descritor, descrição e a compreensão prática do relato que está o cerne da atividade descritiva: os esquemas interpretativos de

11. Idem, p. 91. 
natureza prática funcionam como padrão para a confecção dos relatos que, por sua vez, terminam por corroborar e reelaborar o padrão vigente. Texto e contexto encontram-se em mútua e constante elaboração de tal maneira que nos seria impossível atribuir um significado essencial à natureza dos objetos relatados.

Agora podemos retornar a uma das questões que iniciaram este artigo. Diante da natureza estrutural gestáltica da qual emergem as categorizações, podemos dizer que foram expurgados todos os elementos de caráter indéxico? Certamente não, tendo em vista a natureza interpretativa envolvida no processo de categorização. Isto só é possível com a utilização de algumas estratégias interpretativas. Para efeitos práticos, as atividades do plantão desenrolam-se no terreno das vicissitudes e percalços comuns às atividades práticas de organizações similares. Meu argumento, entretanto, é que o cerne da atividade interpretativa não está na possibilidade ou não de descrições literais, mas na natureza reflexiva que torna possível as descrições ou, em outras palavras, a idéia de que a estrutura gestáltica ordenadora da vida social se articula essencialmente a partir de suas propriedades reflexivas. Esta atividade reflexiva é essencial à sustentação do espaço ontológico em que opera a "razão mundana". Atividades cotidianas e rotineiras de plantonistas requerem práticas que confiram sentido aos fins profissionais para os quais estão sendo formadas, fornecendo um estoque de esquemas interpretativos a partir dos quais será julgado o caráter adequado de suas condutas.

\section{Apêndice}

Texto 1: Fichas de atendimento

\section{Texto 1-a)}

16/4/84 - Plantão diurno.

$5^{\circ}$ caso: ACC, 36 a., masc., melanoderma, natural e procedente de $\mathrm{BH}$.

História de ingestão de quantidade desconhecida de comprimidos não identificados (possivelmente Haldol) e grande quantidade de bebida alcoólica ontem a noite. Hoje começou a apresentar sintomas de impregnação neuroléptica, tendo por isso procurado este serviço. 
Terceira tentativa de auto-extermínio em 1 ano, distúrbio reativo de conduta se apresentou quando descobriu séria moléstia no pai do paciente, tendo sido este episódio desencadeado pela morte da irmã. Relata ter apresentado vômitos ẹsverdeados junto ao aparecimento dos sintomas.

Ao exame apresentava sintomas de impregnação neuroléptica (daí a hipótese do medicamento ser haloperidol), sonolenta, disfásica, confusa. Desidratada (+14+). P.A.: 150/100 mm Hg, sem outras alterações.

I.D. 1) Intoxicação exógena por haloperidol + álcool etílico.

2) Desidratação leve.

Cd 1) Akineton 01 ampola I.V. lento.

2) Hidratação venosa.

3) Orientação + orientação para acompanhante e encamin.

\section{Texto 1-b)}

2/9/85 Plantão diurno.

1. M.S.V.M. amb. 6, 20 anos, solt., fem., morena.

HMA Paciente ingeriu 20 comp. de Diazepan $(7 \mathrm{mg})$, uma hora antes do atendimento, por motivo de desentendimento com o noivo (sic).

Ao exame: sonolenta, letárgica. Bom estado geral. Condições hemodinâmicas/respiratórias estáveis. Queixa-se dolorimento região epigástrica.

I.D. Int. exógena por benzodiazepínico.

CD Lavagem gástrica com 11 soro fisiológico.

Observação ambulatorial. SGI 5\% 500 ml 30gts $/ \mathrm{min}$.

Evolução: Após 6 horas de observação, paciente evoluiu bem.

Alta ambulatorial acompanhada da mãe, após avaliação do clínico. Feita profilaxia das intoxicações e abordado quadro psicológico. 
Texto 1/c)

28/5/85 - (Evolução)

S.S.M., 28 a., UTI Tax. $36,7^{\circ} \mathrm{C}$ PA 110/80mm Pulso 69ppm

FR $21 \mathrm{~m} / \mathrm{min}$.

Acordado, consciente, se dizendo mais tranqüilo. Disse ter tentado morrer devido a problemas que tem tido na vida. É desquitado e tem uma filha de dois anos. Há 7 meses está desempregado, dependendo do pai para sobreviver e não gosta disso. Já fez vários testes para conseguir emprego, em vão. Hoje acha que está mais tranqüilo, já em condições de encarar novamente suas dificuldades (Intoxicação estricnina).

\section{Texto 1-d)}

7/11/85 - $4^{2}$ caso N.L.G., 19 a., Leucoderma. Hora de admissão 19:50 hs.

Paciente com história de "ter brigado com a mãe", e após tentou suicídio com injeção ENDOVENOSA DE $5 \mathrm{ml}$ DE SUA PRÓPRIA URINA. (?) Relatou-me que há muito tempo vem pensando em fazer isto, pois se acha "um ser inútil e inerte na sociedade". É muito nervoso (sic).

Ao exame: Temp. Ax $36^{\circ} \mathrm{C}$; $\mathrm{FC}=1-4 \mathrm{bpm}$. $\mathrm{PA}=120 / 70 \mathrm{~mm} \mathrm{Hg}$

Muito ansioso, chorando muito. Conjuntiva ocular um pouco Hiperemíade e discreto eritrema facial. Sinal função venosa (?) na fossa cubital.

ACV: BNRNF, em 2T, taquicardias.

AR: Eupnéico, MVF preservado.

SN: labilidade emocional, com distúrbios comportamento.

I.D. 1. Tentativa de auto-extermínio.

2. Distúrbio comportament. (potencial suicida) + ansiedade.

3. Alcoolismo agudo.

Cd. Inicial foi observação. 
Paciente permaneceu neste hospital até mais ou menos 22.00, quando o clínico o liberou, pois encontrava-se assintomático, recomendando observação domiciliar, e retornar com mudança do quadro clínico.

Não foi feito encaminhamento do paciente para tratamento especializado (psiquiátrico).

\section{Texto 1-e)}

27/11/85 - Plantão noturno.S.B. 20 a.

Paciente com passado de várias tentativas de suicídio, foi encontrado por colegas, com contrações musculares tônicas, siaborréia, não mantendo diálogo. Evoluiu rapidamente para PCR. O paciente havia dito para seus colegas que iria tomar estricnina.

Ao exame: Paciente em PCR. Midríase fixa, não reativa.

I.D. Intox. exógena por estricnina?

Cd. Administrados: Adrenalina (3 amp)

Xilocaína $1 \%(5 \mathrm{ml})$

Atropina (1mg)

Massagem cardíaca

Entubação orotraqueal

Paciente converteu para ritmo sinusal regular. (óbito em 30/11/85).

\section{Texto 1-f)}

14/6/84 — Plantão noturno.

I - caso. O.M.L., 27 anos, fem., faioderma, casada, natural e procedente de $\mathrm{BH}$, peso $45 \mathrm{~kg}$.

Paciente após discussão com o marido, apanhou um vidro de Malabol e se trancou no banheiro, ameaçando ingerir a substância. Saiu logo depois, dizendo ter ingerido uma "golada" do produto diluído em 
água. Se automedicou com leite e procurou este serviço em seguida. Hora do acidente, 24:00. Hora do atendimento, 1:30. Queixando-se apenas de náusea e queimação epigástrica. Negou vômito e outros sintomas.

Ao exame: paciente consciente, orientada; pupilas isocóricas $3 / 3 \mathrm{~mm}$ (normais) fotorreativas. Boa perfusão capilar. Anietérica, acianótica, afebril. Bom estado geral. Hidratada.

AR: Pulsos cheios, simétricos, rítmicos. BNRNF. FC:85pm.

PA não foi possível obter. Aparelho defeituoso.

abdome: Normotenso, indolor à palpação, peristaltismo discreta/aumentado. Sem viscero-megalia.

AGV: Não examinado.

ID: Intoxicação exógena por organofosforado, tentativa de auto-extermínio.

CD: Por se encontrar o paciente completamente assintomático, sem hálito com odor do componente, optamos por:

- Xarope de Ipeca $20 \mathrm{ml}$ - s/efeito

$-20 \mathrm{~min}$. após xarope de Ipeca - s/efeito

- Lavagem gástrica - SNG n20 + 1000ml de SF a 0,9.

Observamos realização da lavagem: conteúdo gástrico com restos alimentares sem odor característico de OGP. Paciente mantida em observação até as 6:30. Discutimos com o clínico que achou não haver mais necessidade de mais observação. Paciente liberada para casa com orientação.

Obs.: Questionamos a ingestão, pelo menos em dose tóxica, do composto.

\section{RESUMO}

\section{Práticas de Glosa e Anamnese}

As anamneses são essenciais para o estabelecimento de um diagnóstico médico, e consistem em um processo de coletar dados das biografias dos pacientes à luz de uma hipótese. Trata-se de um procedimento essencialmente interpretativo, envolvendo uma relação reflexiva entre as suposições do médico e o comportamento e motivações que poderiam ser associadas ao 
diagnóstico. $\mathrm{O}$ argumento do artigo é o de que existe uma estrutura interpretativa a balizar as hipóteses de diagnóstico que é calcada em procedimentos de senso comum. Para tal, foram analisadas cerca de 140 fichas de atendimentos de tentativas de suicídio realizadas em um Hospital de Pronto Socorro da cidade de Belo Horizonte. Além disso, foram realizadas cerca de 20 observações de atendimentos de pacientes, bem como entrevistas com profissionais responsáveis pelos atendimentos.

\section{RÉSUMÉ}

\section{Conduites de la Glose et de l'Anamnese}

Les anamnèses sont fondamentales pour établir un diagnostique médical. Elles consistent en um processus de recueil de données biographiques des patients, à la lumière d'une hypothèse. Il s'agit essentiellement d'un procédé d'interprétation qui met en jeu une relation entre les suppositions du médecin et le comportement et les motivations qui pourraient être liées au diagnostique. L'article défend la thèse qu'il existe une structure d'interprétation qui permet de délimiter les hypothèses de diagnostique. Cette interprétation repose sur des méthodes de bon sens.

Pour cela, on a procédé à l'analyse d'environ 140 fiches de soins ayant trait à des tentatives de suicides. Ces soins ont été donnés dans un hopital d'urgences de la ville de Belo Horizonte. En outre, on a réalisé, environ 20 observations de soins donnés à des patients, ainsi que des interviews des professionnels responsables des soins.

\section{ABSTRACT}

\section{The Practices of Glossing and Anamnesis}

As a process of gathering patient biographical data from the perspective of a hypothesis, anamneses are essential in establishing a medical diagnosis. Anamneses are basically interpretive procedures that entail a reflective relation between a doctor's suppositions and the behavior and motivations that can be associated to the diagnosis. The article argues that underpinning such diagnostic hypotheses lies an interpretive structure, in turn grounded on common sense procedures. To illustrate this point, an analysis is made 
of some 140 records on individuals who were seen at a Belo Horizonte hospital emergency room following suicide attempts. In addition, about 20 consultations with patients were observed, and the professionals providing consultations were interviewed. 